\title{
Manic behavior and asymmetric right frontotemporal dementia from a novel progranulin mutation
}

This article was published in the following Dove Press journal:

Neuropsychiatric Disease and Treatment

\author{
Mario F Mendez ${ }^{1-3}$ \\ 'Department of Neurology, \\ ${ }^{2}$ Department of Psychiatry \& \\ Biobehavioral Sciences, David Geffen \\ School of Medicine, University of \\ California at Los Angeles, Los Angeles, \\ CA, USA ${ }^{3}$ Neurology Service, VA \\ Greater Los Angeles Healthcare \\ System, Los Angeles, CA, USA
}

\begin{abstract}
Studies suggest a relationship of manic behavior and bipolar disorder (BD) with behavioral variant frontotemporal dementia (bvFTD). The nature of this relationship is unclear. This report presents a patient with initial manic behavior as the main manifestation of familial bvFTD from a novel progranulin (GRN) mutation. In contrast, there are other reports of a long background of BD preceding a diagnosis of bvFTD. A review of the literature and this patient suggest that manic symptoms result from damage to right frontotemporal neural structures from longstanding BD, as well as from bvFTD and other focal neurological disorders. In addition, there is a subgroup of patients with a probable genetic predisposition to both BD and bvFTD. Keywords: frontotemporal dementia, mania, bipolar disorder, progranulin mutation
\end{abstract}

\section{Introduction}

Behavioral variant frontotemporal dementia (bvFTD) is a neurodegenerative disorder that can present with subtle alterations of personality. ${ }^{1}$ The onset is usually insidious in mid-life, with progression to severe dementia caused by atrophy of the frontal and anterior temporal lobes. Most commonly, patients develop apathy or abulia, disinhibition or impulsivity, loss of sympathy or empathy, compulsions and stereotypies, and dietary changes, particularly carbohydrate cravings. ${ }^{1}$ Many, if not most, patients with bvFTD present to psychiatrists and other mental health specialists with concerns over depression, anxiety, mid-life crisis, and other conditions, before a neurodegenerative brain disorder is considered. ${ }^{2}$ The early diagnosis and management of bvFTD depends on recognizing the range of initial and presenting signs and symptoms of this disorder. This report presents a familial bvFTD patient who initially developed manic symptoms, and reviews the literature on the relationship of bipolar symptoms and bvFTD. Written informed consent was provided by the patient's husband, who is the legal guardian for this case report and any accompanying images.

\section{Case report}

A 63-year-old right-handed woman with 16 years of education had a 2-year history of personality change, characterized as becoming increasing rude in conversation. Her husband reported that she would constantly interrupt and talk out of turn, speaking rapidly about topics tangential to the conversation. Her thoughts and speech would then go from one unrelated topic to another. This change was the husband's main complaint, with an immediate precipitating event being the exclusion from her social group at her country club. Her husband described her as having an "acquired attention
Correspondence: Mario F Mendez Neurobehavior (69I/I I6AF), VA Greater Los Angeles Healthcare Center, II 30 I Wilshire Blvd., Los Angeles, CA 90073 , USA

Tel + I 31047837 II ext 42696

$\mathrm{Fax}+\mid 3102684181$

Emailmmendez@ucla.edu 
deficit hyperactivity behavior", with decreased attention span and concentration, hyperactivity and fidgetiness, and restless inability to sit still for any prolonged period of time. He further described her as having diminished empathy or responsiveness to others' feelings, and impulsive or inappropriate behavior, such as making offensive remarks and uncharacteristic arguments with peers. He observed her having difficulties with organization, multitasking, and following a sequence of steps to complete a task, such as cooking a meal. She was mostly independent in her routine and instrumental activities of daily living. The patient herself stated: "I am not aware of any changes. I just need to keep walking. I cannot sit still". The review of psychiatric and neurological systems was negative for decreased need for sleep, increased goal-directed activity, risky behavior, compulsive-like acts, or dietary changes. Her past medical history was otherwise negative, but her family history was positive for an affected brother with an unknown "dementia" at age 68 and early dementia in her mother's family (her mother died relatively young of colon cancer).

On examination, she appeared restless, constantly moving, and hyperactive. Her speech was intrusive with tangential verbal output. She would quickly lapse into a totally unrelated story, going rapidly from one topic to another, appearing derailed by any transient idea or thought. Much of her rapid speech was imperfectly spoken with omitted words. Her mood and affect appeared euthymic, and there was no evidence of an expansive or euphoric mood, grandiosity, or inflated self-esteem. There was no evidence of a formal thought disorder or psychotic features.

On her neurocognitive assessment, she was oriented in all spheres and had 26/30 on the Mini-Mental State Examination, ${ }^{3}$ missing memory items and the intersecting pentagons. When asked to slow down, however, she could do a good drawing, despite tending to rush through the tasks. Attention testing showed a digit span of 5 forward, but only 1 in reverse, and she was quickly derailed on any vigilance test. Her language was fluent, with normal comprehension, repetition, and confrontational naming, and she had word lists of 12 animals/min and nine " $F$ " words/min. On an auditory verbal learning test, she recalled $7 / 10$ words at $15 \mathrm{~min}$, with recognition of 10/10. Her remote memory and knowledge of current events were intact. On visuospatial testing, she had disproportionate difficulty with faces, recognizing only 14 of 26 famous faces. Single-digit and double-digit addition and multiplication were normal, and there was no limb apraxia. The patient gave concrete interpretations to proverbs such as "people in glass houses shouldn't throw stones" (eg, "the glass would break"). On the Frontal Assessment Battery, ${ }^{4}$ she scored 15/18; the patient was able to complete alternating tapping, and the GoNoGo test, but got only two of six trials on the Luria alternating hand sequences. She was normal on the rest of the neurological examination, including cranial nerves, gait and coordination, motor, sensation, and reflexes.

The patient underwent a series of diagnostic tests. Routine blood laboratory tests were normal. Neuropsychological assessment showed predominant evidence of decreased executive functions in processing speed, mental shifting, auditory working memory, and the ability to efficiently shift cognitive set. Performance on these executive tests was generally $<1$ st percentile compared to tests of language (48th for animal list verbal fluency), visuospatial abilities ( 5 th for block design), and memory (69th for long delay free recall). Her magnetic resonance imaging (MRI) and fluorodeoxyglucose positron emission tomography (PET) imaging showed asymmetric, predominant right frontotemporal degeneration and hypometabolism, although there was significant involvement of the left temporal lobe as well right parietal hypometabolism on PET (see Figure 1).

The patient was diagnosed with right frontotemporal predominant bvFTD, based on a progressive deterioration of behavior with early disinhibition and social impropriety, diminished empathy, predominant executive neuropsychological deficits, and supportive neuroimaging. Genetic testing for the major FTD genes revealed a novel progranulin nonsense mutation (c.6 G>A; p.Trp2X). The patient subsequently progressed, developing other features of bvFTD such as carbohydrate craving and compulsive-like behaviors, which partially responded to sertraline at doses up to $200 \mathrm{mg} /$ day.

\section{Discussion}

This patient presented with manic behavior, and proved to have a predominant right frontotemporal variant of bvFTD. She had press of speech, flight of ideas, distractibility to irrelevant external stimuli, and psychomotor agitation. She did not have other manic symptoms, such as a truly elevated mood with inflated self-esteem or grandiosity, decreased need for sleep, or increased goal-directed or risky behaviors; hence, she did not fulfill all criteria for mania. ${ }^{5}$ She was tangential in her conversation, and showed "derailment", a process where she would go off on her own with loosely related or totally unrelated commentary. Finally, neuroimaging revealed predominant right frontotemporal involvement, with relative sparing of the left frontal lobe.

This patient has a novel mutation in the progranulin (GRN) gene on chromosome 17. GRN mutations make up 5\%-10\% of known familial frontotemporal degenerations, compared to 

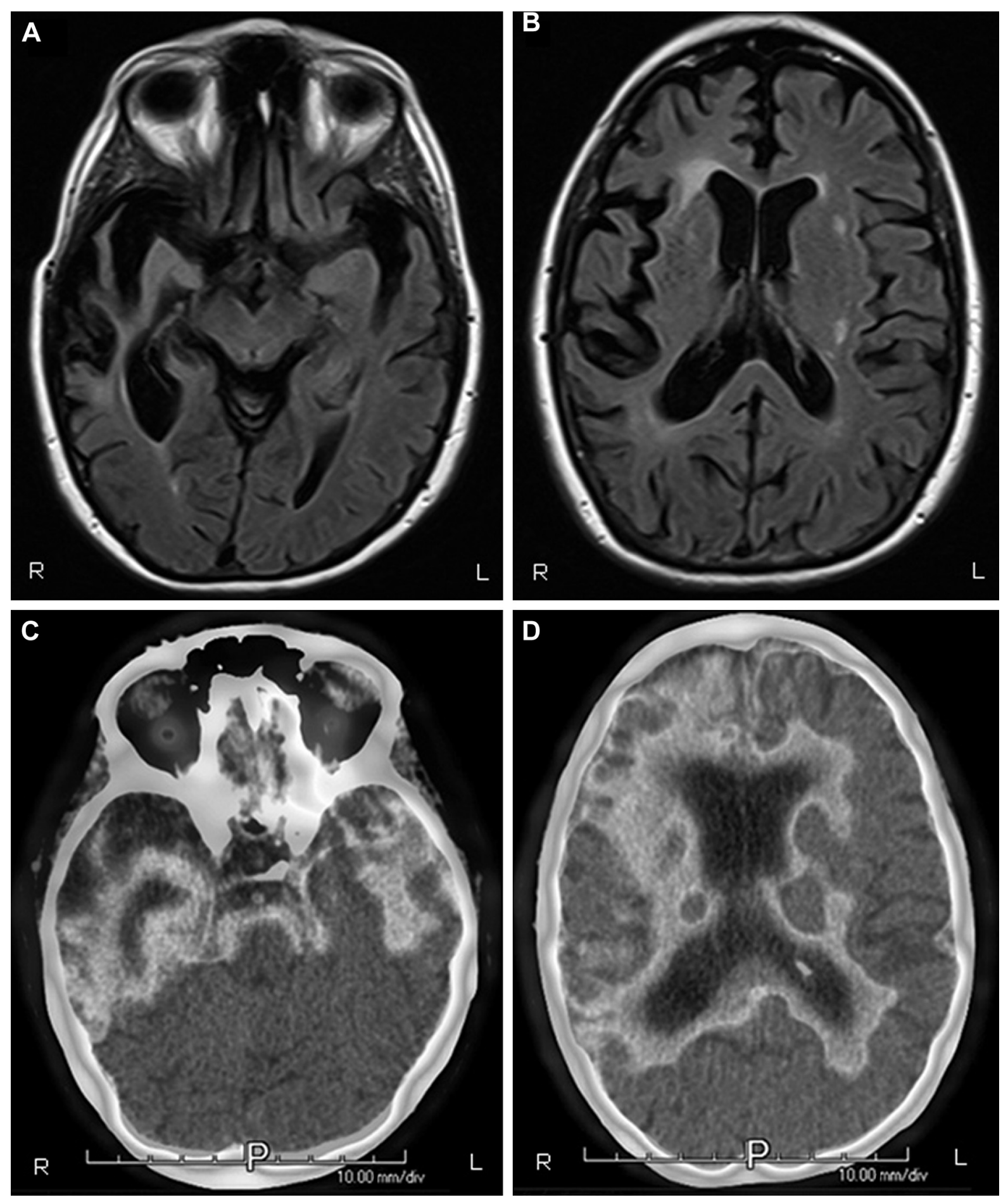

Figure I (A and B) MRI of brain, axial T2 Flair view, showing prominent bitemporal, right greater than left, atrophy. (C and D) PET imaging illustrating bitemporal and right frontal hypometabolism. There is extension of the hypometabolism to the right parietal lobe. All images are radiological convention with the left hemisphere on the right and the right hemisphere on the left.

Abbreviations: R, right; L, left; P, posterior; MRI, magnetic resonance imaging; PET, positron emission tomography.

$12 \%$ from chromosome 9 open frame reduction 72 (C9orf72) and $2 \%-11 \%$ from microtubular-associated protein tau (MAPT) mutations. ${ }^{6}$ This patient's GRN mutation (c.6 G > A; p.Trp2X) adds to the approximate 172 known GRN mutations (http://www.molgen.ua.ac.be/). GRN mutations are autosomal dominant, with about $95 \%$ having an affected parent, ${ }^{6}$ which is not reported in this patient, probably because of her mother's early death from cancer. The GRN gene encodes for progranulin, a precursor protein that is eventually cleaved into granulins, which regulate cell growth and participate in wound healing and tumorigenesis. GRN mutations result in haploinsufficiency, with a decrease in granulin production. 
Patients with GRN mutations have an average age of onset of 62 years, but age of onset can range from 35 to 87 years, with a disease duration of $3-12$ years. ${ }^{6}$ They most commonly present with behavioral disorders consistent with bvFTD, but can also present with nonfluent variant primary progressive aphasia (nfvPPA), a related frontotemporal degeneration. GRN mutations specifically tend to prominent asymmetry, especially with bitemporal asymmetry atrophy and involvement of the insula, parietal lobe, and striatum.

This patient illustrates the relationship of manic behavior, a major manifestation of the bipolar spectrum, and bvFTD. Although strict application of criteria for formal psychiatric disorders can exclude bipolar disorder, ${ }^{7}$ the symptoms of mania and bvFTD overlap, and there are a number of reports of manic behavior as an initial manifestation of bvFTD. ${ }^{2,8-13}$ Studies have shown a relationship of "acquired extroversion" and manic-like euphoria with a right temporal predominant bvFTD, ${ }^{14,15}$ and these patients may have press of speech, tangentiality, derailment, and even clanging and punning. ${ }^{14}$ This patient's press of speech and other manic symptoms, are also consistent with the spectrum of behavioral disinhibition, one of the commonest manifestations of bvFTD. ${ }^{1,16,17}$ Some disinhibited behaviors in bvFTD are highly associated with violations of social tact and personal boundaries, ${ }^{16,18}$ as in this patient. Among patients with bvFTD, investigators report disinhibition associated with decreased volumes in the right amygdala, right ventromedial prefrontal cortex, and right anterior temporal cortex. ${ }^{19}$

Patients with manic symptoms and bvFTD highlight the complex relationship between the bipolar spectrum and bvFTD. There appears to be an increased risk of bvFTD and nfvPPA before age 60 in those with BD, with documented cases of patients with a lifelong diagnosis of BD evolving to these frontotemporal degenerations..$^{20-22}$ In these patients, there may be a shared genetic predisposition to both $\mathrm{BD}$ and bvFTD, as previously noted from C9orf72 mutations. ${ }^{23}$ Investigators have reported $\mathrm{C} 9$ orf 72 mutations in patients with BD preceding bvFTD, with possible genetic expansion from BD to bvFTD. ${ }^{23}$ The absence of C9orf72 mutations among a cohort of 206 patients with BD further indicates that this occurrence is rare. ${ }^{24}$ Other investigators have reported GRN mutations in patients with late onset $\mathrm{BD}$ or with bipolar spectrum disorders preceding the development of bvFTD or nfvPPA. ${ }^{21,25}$ The presence of lower progranulin plasma levels among some patients with BD may also suggest a relationship of GRN mutations with bipolar spectrum disorders. $^{26-29}$
Beyond a common genetic predisposition in some patients, there may be a more common causal relationship of bipolar symptoms with an FTD-like dementia. Among the major psychiatric syndromes, BD is most frequently associated with neurocognitive decline (verbal memory, executive, verbal fluency) and dementia, ${ }^{30}$ and both patients with bvFTD and elderly BD patients have deficits in executive functions. ${ }^{31,32}$ The cumulative neurotoxicity of manic and depressive episodes over decades could potentially result in persistent cognitive deterioration during the euthymic phase, frontally predominant cognitive and behavioral changes, and an eventual "bipolar" and non-progressive dementia that mimics bvFTD. ${ }^{12,19,33,34}$ This is consistent with four patients with manifestations of BD type I at least 10 years before onset of bvFTD-like symptoms. ${ }^{35}$ These four patients had 3-7 years of follow-up without a progressive neurodegenerative course or changes on neuroimaging. ${ }^{35}$

The most probable association of bvFTD and manic behavior is a common dysfunction of right frontotemporal neuroanatomical structures involved in emotional behavior. ${ }^{36,37}$ Abnormal volumes and blood flow in frontal and temporal cortical areas are common neuropathological findings in bvFTD that may occur with BD. "Secondary mania" has resulted from strokes and other neurological lesions specifically involving the right inferolateral frontal and right basotemporal regions. ${ }^{39-41}$ Mania may even follow right temporal epileptiform discharges. ${ }^{42}$ Moreover, right frontal disease can result in grandiosity, impulsivity, tangentiality with digressions, and free association of ideas to the point of confabulation. ${ }^{43-45}$ Together, these findings suggests that manic behavior originates from right-hemisphere frontotemporal-limbic dysfunction and that, in this case report, this neuroanatomic involvement is more important in producing manic-like behavior than the GRN mutation. ${ }^{39}$

In conclusion, the relationship of mania and BD with bvFTD is heterogeneous. Manic symptoms result not only from right frontotemporal disease due to bvFTD and other focal neurological disorders, but also as part of a frontallypredominant cognitive decline in patients with longstanding BD. This last "bipolar dementia" is often mild, non-progressive, and may mimic bvFTD. In some individuals, there also appears to be an association of BD with the frontotemporal degenerations, possibly due to a shared genetic predisposition from mutations in the GRN, C9orf72, or other genes. These are intriguing conclusions, but they are preliminary. We need much more research in order to clearly define the important relationship of bipolar spectrum disorders and bvFTD. 


\section{Acknowledgment}

The author acknowledges the following funding from the National Institute of Aging: R01AG050967 and R01 AG034499.

\section{Disclosure}

The author reports no conflicts of interest in this work.

\section{References}

1. Rascovsky K, Hodges JR, Knopman D, et al. Sensitivity of revised diagnostic criteria for the behavioural variant of frontotemporal dementia. Brain. 2011;134(Pt 9):2456-2477.

2. Woolley JD, Khan BK, Murthy NK, Miller BL, Rankin KP. The diagnostic challenge of psychiatric symptoms in neurodegenerative disease: rates of and risk factors for prior psychiatric diagnosis in patients with early neurodegenerative disease. J Clin Psychiatry. 2011;72(2):126-133

3. Folstein MF, Folstein SE, McHugh PR. "Mini-mental state”. A practical method for grading the cognitive state of patients for the clinician. J Psychiatr Res. 1975;12(3):189-198.

4. Slachevsky A, Villalpando JM, Sarazin M, Hahn-Barma V, Pillon B, Dubois B. Frontal assessment battery and differential diagnosis of frontotemporal dementia and Alzheimer disease. Arch Neurol. 2004;61(7): 1104-1107.

5. American Psychiatric Association. Diagnostic and Statistical Manual of Mental Disorders, Fifth Edition (DSM-5®). Washington, D.C.: American Psychiatric Association; 2013. Available from: http://JHU eblib.com/patron/FullRecord.aspx?p=1811753

6. Hsiung GYR, Feldman HH. GRN-related frontotemporal dementia. In: Adam MP, Ardinger HH, Pagon RA, et al, editors. GeneReviews $(R)$. Seattle, WA: University of Washington; 1993.

7. Gossink FT, Dols A, Krudop WA, et al. Formal psychiatric disorders are not overrepresented in behavioral variant frontotemporal dementia J Alzheimers Dis. 2016;51(4):1249-1256.

8. Vorspan F, Bertoux M, Brichant-Petitjean C, Dubois B, Lepine JP. Relapsing-remitting behavioural variant of frontotemporal dementia in a bipolar patient. Funct Neurol. 2012;27(3):193-196.

9. Kerstein AH, Schroeder RW, Baade LE, Lincoln J, Khan AY. Frontotemporal dementia mimicking bipolar disorder. J Psychiatr Pract. 2013;19(6):498-500.

10. Chow TW, Miller BL, Hayashi VN, Geschwind DH. Inheritance of frontotemporal dementia. Arch Neurol. 1999;56(7):817-822.

11. Woolley JD, Wilson MR, Hung E, Gorno-Tempini ML, Miller BL, Shim J. Frontotemporal dementia and mania. Am J Psychiatry. 2007; 164(12):1811-1816.

12. Monji A, Motomura K, Mizoguchi Y, et al. A case of late-onset bipolar disorder with severely abnormal behavior and neuroimaging observations very similar to those of frontotemporal dementia. J Neuropsychiatry Clin Neurosci. 2014;26(1):E35.

13. Galimberti D, Dell'Osso B, Altamura AC, Scarpini E. Psychiatric symptoms in frontotemporal dementia: epidemiology, phenotypes, and differential diagnosis. Biol Psychiatry. 2015;78(10):684-692.

14. Mendez MF, Carr AR, Paholpak P. Psychotic-like speech in frontotemporal dementia. J Neuropsychiatry Clin Neurosci. 2017;29(2): $183-185$.

15. Mendez MF, Chen AK, Shapira JS, Lu PH, Miller BL. Acquired extroversion associated with bitemporal variant of frontotemporal dementia. J Neuropsychiatry Clin Neurosci. 2006;18(1):100-107.

16. Paholpak P, Carr AR, Barsuglia JP, et al. Person-based versus generalized impulsivity disinhibition in frontotemporal dementia and Alzheimer disease. J Geriatr Psychiatry Neurol. 2016;29(6): 344-351.
17. Perri R, Monaco M, Fadda L, Caltagirone C, Carlesimo GA. Neuropsychological correlates of behavioral symptoms in Alzheimer's disease, frontal variant of frontotemporal, subcortical vascular, and lewy body dementias: a comparative study. J Alzheimers Dis 2014;39(3):669-677.

18. Starkstein SE, Garau ML, Cao A. Prevalence and clinical correlates of disinhibition in dementia. Cogn Behav Neurol. 2004;17(3):139-147.

19. Liu W, Miller BL, Kramer JH, et al. Behavioral disorders in the frontal and temporal variants of frontotemporal dementia. Neurology. 2004;62(5):742-748.

20. Papazacharias A, Lozupone M, Barulli MR, et al. Bipolar disorder and frontotemporal dementia: an intriguing association. J Alzheimer's Dis. 2017;55(3):973-979.

21. Cerami C, Marcone A, Galimberti D, Villa C, Scarpini E, Cappa SF. From genotype to phenotype: two cases of genetic frontotemporal lobar degeneration with premorbid bipolar disorder. J Alzheimer's Dis. 2011;27(4):791-797.

22. Pavlovic A, Marley J, Sivakumar V. Development of frontotemporal dementia in a case of bipolar affective disorder: is there a link? BMJ Case Rep. 2011; doi: 10.1136/bcr.09.2010.3303.

23. Meisler MH, Grant AE, Jones JM, et al. C9ORF72 expansion in a family with bipolar disorder. Bipolar Disord. 2013;15(3):326-332.

24. Floris G, Borghero G, Cannas A, et al. Bipolar affective disorder preceding frontotemporal dementia in a patient with C9ORF72 mutation: is there a genetic link between these two disorders? J Neurol. 2013;260(4):1155-1157.

25. Rubino E, Vacca A, Gallone S, et al. Late onset bipolar disorder and frontotemporal dementia with mutation in progranulin gene: a case report. Amyotroph Lateral Scler Frontotemporal Degener. 2017;18(7-8):1-3.

26. Galimberti D, Dell'Osso B, Fenoglio C, et al. Progranulin gene variability and plasma levels in bipolar disorder and schizophrenia. PloS One. 2012;7(4):e32164.

27. Galimberti D, Prunas C, Paoli RA, et al. Progranulin gene variability influences the risk for bipolar I disorder, but not bipolar II disorder. Bipolar Disord. 2014;16(7):769-772.

28. Kittel-Schneider S, Weigl J, Volkert J, et al. Further evidence for plasma progranulin as a biomarker in bipolar disorder. J Affect Disord. 2014;157:87-91

29. Buttenschon HN, Nielsen MN, Thotakura G, et al. Progranulin gene variation affects serum progranulin levels differently in Danish bipolar individuals compared with healthy controls. Psychiatr Genet. 2017;27(3):89-95.

30. Meesters PD, Schouws S, Stek M, et al. Cognitive impairment in late life schizophrenia and bipolar I disorder. Int J Geriatr Psychiatry. 2013;28(1):82-90.

31. Baez S, Pinasco C, Roca M, et al. Brain structural correlates of executive and social cognition profiles in behavioral variant frontotemporal dementia and elderly bipolar disorder. Neuropsychologia. Epub 2017 Feb 17.

32. Vijverberg EGB, Schouws S, Meesters PD, et al. Cognitive deficits in patients with neuropsychiatric symptoms: a comparative study between behavioral variant frontotemporal dementia and primary psychiatric disorders. J Clin Psychiatry. 2017;78(8):e940-e946.

33. Lebert F, Lys H, Haem E, Pasquier F. [Dementia following bipolar disorder]. LEncephale. 2008;34(6):606-610.

34. Masouy A, Chopard G, Vandel P, et al. Bipolar disorder and dementia: where is the link? Psychogeriatrics. 2011;11(1):60-67.

35. Dols A, Krudop W, Moller C, Shulman K, Sajatovic M, Pijnenburg YA. Late life bipolar disorder evolving into frontotemporal dementia mimic. Neuropsychiatr Dis Treat. 2016;12:2207-2212.

36. Zhou J, Seeley WW. Network dysfunction in Alzheimer's disease and frontotemporal dementia: implications for psychiatry. Biol Psychiatry. 2014;75(7):565-573.

37. Lois G, Linke J, Wessa M. Altered functional connectivity between emotional and cognitive resting state networks in euthymic bipolar I disorder patients. PloS One. 2014;9(10):e107829. 
38. Strakowski SM, Delbello MP, Adler CM. The functional neuroanatomy of bipolar disorder: a review of neuroimaging findings. Mol Psychiatry. 2005;10(1):105-116.

39. Satzer D, Bond DJ. Mania secondary to focal brain lesions: implications for understanding the functional neuroanatomy of bipolar disorder. Bipolar Disord. 2016;18(3):205-220.

40. Mendez MF. Mania in neurologic disorders. Curr Psychiatry Rep. 2000;2(5):440-445

41. Gafoor R, O'Keane V. Three case reports of secondary mania: evidence supporting a right frontotemporal locus. Eur Psychiatry. 2003;18(1):32-33.
42. Hurwitz TA, Wada JA, Kosaka BD, Strauss EH. Cerebral organization of affect suggested by temporal lobe seizures. Neurology. 1985;35(9):1335-1337.

43. Ziauddeen H, Dibben C, Kipps C, Hodges JR, McKenna PJ. Negative schizophrenic symptoms and the frontal lobe syndrome: one and the same? Eur Arch Psychiatry Clin Neurosci. 2011;261(1):59-67.

44. Alexander MP, Benson DF, Stuss DT. Frontal lobes and language. Brain Lang. 1989;37(4):656-691.

45. Novoa OP, Ardila A. Linguistic abilities in patients with prefrontal damage. Brain Lang. 1987;30(2):206-225.

\section{Publish your work in this journal}

Neuropsychiatric Disease and Treatment is an international, peerreviewed journal of clinical therapeutics and pharmacology focusing on concise rapid reporting of clinical or pre-clinical studies on a range of neuropsychiatric and neurological disorders. This journal is indexed on PubMed Central, the 'PsycINFO' database and CAS, and is the official journal of The International Neuropsychiatric Association (INA). The manuscript management system is completely online and includes a very quick and fair peer-review system, which is all easy to use. Visit http://www.dovepress.com/testimonials.php to read real quotes from published authors.

Submit your manuscript here: http://www.dovepress.com/neuropsychiatric-disease-and-treatment-journal 